\title{
Targeting Pseudomonas aeruginosa in the Sputum of Primary Ciliary Dyskinesia Patients with a Combinatorial Strategy Having Antibacterial and Anti-Virulence Potential
}

\author{
Giuseppantonio Maisetta ${ }^{1, *}$, Lucia Grassi ${ }^{1}$, Semih Esin ${ }^{1}$, Esingül Kaya ${ }^{1}$, Andrea Morelli ${ }^{2}$, \\ Dario Puppi ${ }^{2}{ }^{\circledR}$, Martina Piras ${ }^{3}$, Federica Chiellini ${ }^{2}$, Massimo Pifferi ${ }^{3}$ and Giovanna Batoni ${ }^{1}$ \\ 1 Department of Translational Research and New Technologies in Medicine and Surgery, University of Pisa, \\ 56123 Pisa, Italy; lucia.grassi@med.unipi.it (L.G.); semih.esin@med.unipi.it (S.E.); \\ esingulkaya@gmail.com (E.K.); giovanna.batoni@med.unipi.it (G.B.) \\ 2 Department of Chemistry and Industrial Chemistry, University of Pisa, 56124 Pisa, Italy; \\ a.morelli@dcci.unipi.it (A.M.); d.puppi@dcci.unipi.it (D.P.); federica.chiellini@unipi.it (F.C.) \\ 3 Section of Pneumology and Allergology, Unit of Pediatrics, Pisa University Hospital, 56126 Pisa, Italy; \\ martinaprs@gmail.com (M.P.); m.pifferi@med.unipi.it (M.P.) \\ * Correspondence: giuseppantonio.maisetta@dps.unipi.it; Tel.: +39-050-2213692; Fax: +39-050-2213711
}

Received: 2 December 2019; Accepted: 17 December 2019; Published: 20 December 2019

\begin{abstract}
In primary ciliary dyskinesia (PCD) patients, Pseudomonas aeruginosa is a major opportunistic pathogen, frequently involved in chronic infections of the lower airways. Infections by this bacterial species correlates with a worsening clinical prognosis and recalcitrance to currently available therapeutics. The antimicrobial peptide, lin-SB056-1, in combination with the cation chelator ethylenediaminetetraacetic acid (EDTA), was previously demonstrated to be bactericidal against $P$. aeruginosa in an artificial sputum medium. The purpose of this study was to validate the anti-P. aeruginosa activity of such a combination in PCD sputum and to evaluate the in vitro anti-virulence effects of EDTA. In combination with EDTA, lin-SB056-1 was able to significantly reduce the load of endogenous P. aeruginosa ex vivo in the sputum of PCD patients. In addition, EDTA markedly reduced the production of relevant bacterial virulence factors (e.g., pyocyanin, proteases, LasA) in vitro by two representative mucoid strains of $P$. aeruginosa isolated from the sputum of PCD patients. These results indicate that the lin-SB056-1/EDTA combination may exert a dual antimicrobial and anti-virulence action against $P$. aeruginosa, suggesting a therapeutic potential against chronic airway infections sustained by this bacterium.
\end{abstract}

Keywords: antimicrobial peptide; EDTA; Pseudomonas aeruginosa; primary ciliary dyskinesia; virulence factor; anti-virulence; sputum; chronic infection

\section{Introduction}

Primary ciliary dyskinesia (PCD) is an autosomal recessive disorder characterized by abnormal ciliary ultrastructure and function leading to impaired mucociliary clearance and recurrent respiratory infections [1]. Although Haemophilus influenzae is the pathogen most commonly isolated from patients with PCD until adolescence/early adulthood, in adult PCD patients, P. aeruginosa plays a major role, especially after the age of 30 [1]. Accordingly, a negative correlation between the abundance of $P$. aeruginosa in the airways of these patients and lung function has been reported $[2,3]$. The pathogenesis of $P$. aeruginosa infection is at least partially attributable to its ability to synthesize and secrete a number of virulence factors (e.g., pyoverdine, pyocyanin, proteases) and to form biofilms, in which bacterial 
cells are embedded in an alginate extracellular matrix [4]. Despite intensive antibiotic therapy, once the patients are stably colonized by P. aeruginosa, the eradication of the bacterium is rarely achieved $[1,5]$. Therefore, there is a critical need for novel antimicrobial drugs that can effectively lower P. aeruginosa load in the challenging environment of PCD lung.

Over the last decades, antimicrobial peptides (AMPs) have been intensively investigated as potential antibiotics against multidrug-resistant bacteria [6]. Most AMPs are cationic molecules with an amphipathic structure that selectively target bacterial membranes via electrostatic forces. In contrast to standard antibiotics, AMPs are generally effective against both quiescent and actively growing bacteria, display rapid killing kinetics, and demonstrate low propensity to select resistant mutants in vitro $[7,8]$. On the other hand, AMPs may display a reduction in their antibacterial potency in the presence of complex biological fluids such as sputum, plasma, or saliva due to the high concentration of salt found in these fluids and/or the presence of anionic proteins and host or bacterial proteases that may neutralize their activity $[9,10]$.

As observed in cystic fibrosis (CF) lungs, the biofilm mode of growth of bacteria together with the lung mucus viscosity reduces the effectiveness of conventional antibiotic therapy in PCD patients [11]. Thus, the usage of adjuvants has been proposed to improve the diffusion of antimicrobials through the mucus and the biofilm matrix and facilitate the targeting of bacterial cells [12]. Previous studies have shown that the divalent cation chelator ethylenediaminetetraacetic acid (EDTA) can destabilize the biofilm structure by interfering with the ionic attractive forces among the biofilm matrix components $[13,14]$. EDTA is prescribed in a number of clinical conditions demonstrating high tolerability (up to $2 \mathrm{~g}$ once a week, intravenously injected) and efficacy [15]. Recently, we demonstrated that the optimized semi-synthetic antimicrobial peptide lin-SB056-1 in combination with EDTA is able to exert a synergistic bactericidal effect against $P$. aeruginosa in an artificial sputum medium resembling CF sputum [16]. Similarities and differences between CF and PDC sputum have been reported. For instance, while both diseases seem to be associated with a similar degree of airways neutrophilia, the concentration of interleukin-8 in sputum is higher in PCD than in CF patients, while neutrophil elastase activity is lower in PCD compared with CF [17]. In order to evaluate the therapeutic potential of the lin-SB056-1/EDTA combination in PCD, in this study, we evaluated its bactericidal activity ex vivo, against endogenous P. aeruginosa in the sputum from PCD patients. Importantly, the ex vivo sputum mimics, with good approximation, the lung environment, as it contains both host and bacterial components, including bronchial mucus contaminated by saliva, serum proteins, inflammatory mediators, desquamated epithelial cells, and pathogenic bacteria, as well as bacteria from the normal flora [18].

Previous reports have demonstrated the involvement of different cations (i.e., calcium, magnesium, and zinc) either in the regulation of gene expression or in the production and processing of virulence factors in P. aeruginosa $[19,20]$. Thus, herein, we also evaluated the ability of EDTA to reduce the production of relevant virulence factors of P. aeruginosa (e.g., pyoverdin, pyocyanin, proteases, biofilm production). Overall, the results obtained demonstrated that the lin-SB056-1/EDTA combination is able to significantly reduce $P$. aeruginosa load ex vivo and that EDTA is highly active in suppressing the production of relevant bacterial virulence factors, suggesting a dual antibacterial and anti-virulence potential of the combination.

\section{Results}

\subsection{Killing Activity of lin-SB056-1 in Combination with Ethylenediaminetetraacetic Acid (EDTA) against Endogenous P. aeruginosa}

P. aeruginosa strains were isolated from the sputum of six PCD patients known to be chronically infected with the bacterium. All the strains displayed a mucoid phenotype and different antibiotic susceptibility profiles (Supplementary Table S1).

Diluted sputum (5-fold) from each patient was incubated for $1.5 \mathrm{~h}$ with the peptide at $25 \mu \mathrm{g} / \mathrm{mL}$, alone or in combination with EDTA ( 0.625 or $1.25 \mathrm{mM}$ ), and the colony forming unit (CFU) number 
of $P$. aeruginosa surviving the treatment was detected. During the incubation time, endogenous $P$. aeruginosa did not grow in PCD sputum. While the peptide and EDTA were almost inactive when used alone, their combination exerted a significant synergistic killing effect against endogenous P. aeruginosa, although with different efficacy depending on the sputum sample (Figure 1). When compared to the corresponding controls, the reduction in CFU number caused by the combination ranged from approximately $0.3 \mathrm{Log}$-units (50\% reduction, grey dot) to 3 Log-units (99.9\% reduction, blue triangle) (Figure 1).

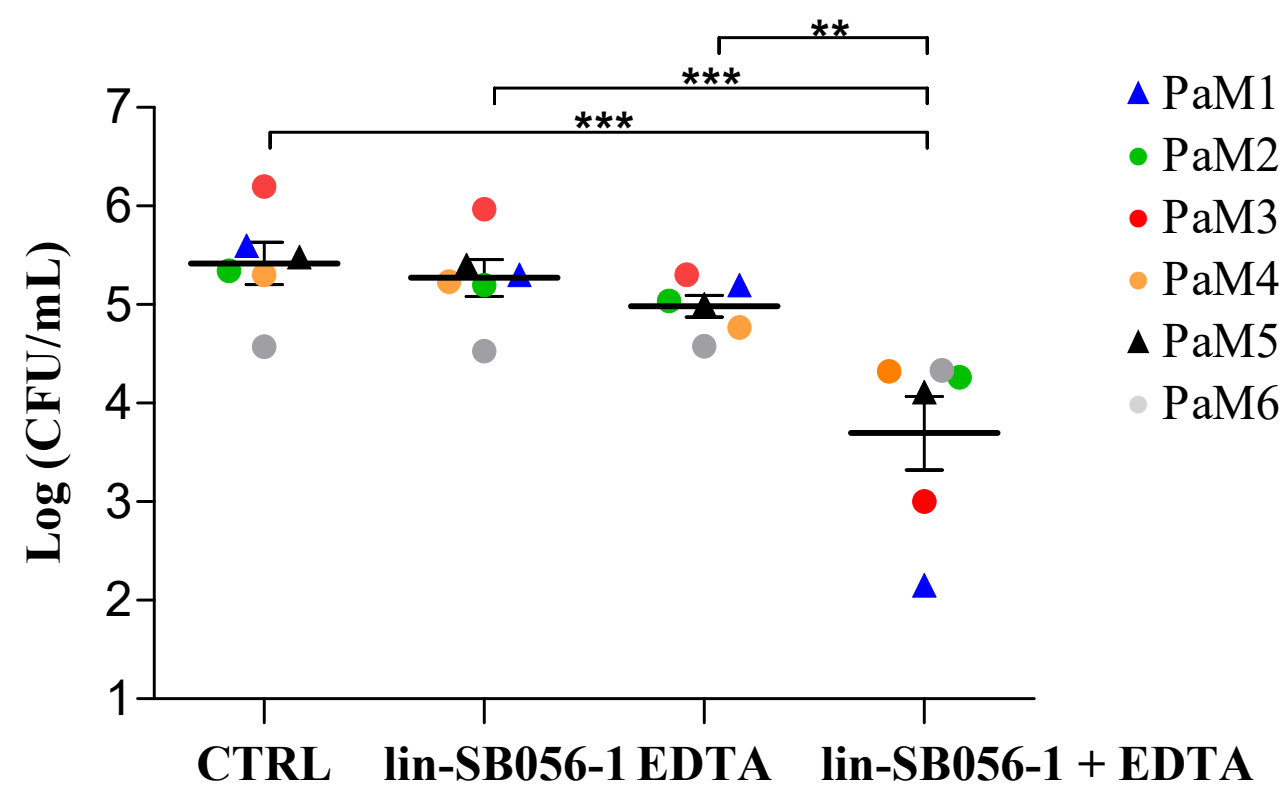

Figure 1. Antibacterial activity of peptide lin-SB056-1, ethylenediaminetetraacetic acid (EDTA), and both in combination against endogenous P. aeruginosa in primary ciliary dyskinesia (PCD) sputum. The effect of lin-SB056-1 and/or EDTA after $1.5 \mathrm{~h}$ of incubation in six diluted (1:5) sputum samples was assessed against endogenous P. aeruginosa strains (PaM1 to PaM6) by colony forming unit (CFU) counting. Lin-SB056-1 was tested at $25 \mu \mathrm{g} / \mathrm{mL}$ in combination with $0.625 \mathrm{mM}$ EDTA against PaM1 and PaM5 strains (triangles), and with 1.25 mM EDTA against PaM2, PaM3, PaM4, and PaM6 strains (dots). Control (CTRL): bacteria incubated in diluted sputum only. Individual sputum samples are identified with different colors. Results represent the mean of 6 sputa done in duplicate. Error bars indicate the standard error of the mean. ${ }^{* *} p<0.01,{ }^{* * *} p<0.001$ (one-way analysis of variance (ANOVA) followed by the Tukey-Kramer post-hoc test).

\subsection{Effects of EDTA and lin-SB056-1 on Virulence Factors' Production by P. aeruginosa PaM1 and PaM5}

Preliminary experiments indicated that PaM1and PaM5 strains are able to produce high levels of most of the virulence factors analyzed; therefore, these strains were selected to evaluate the effect of sub-inhibitory concentrations of EDTA on virulence factors' production. To this aim, we first evaluated the susceptibility of PaM1 and PaM5 strains to EDTA in liquid medium, in terms of minimum inhibitory concentration (MIC). A concentration of 1.25 mM EDTA was able to inhibit visible bacterial growth (MIC), while the concentrations of 0.075 and $0.15 \mathrm{mM}$ were sub-inhibitory and therefore, were selected for the subsequent experiments.

Pyocyanin is a greenish pigment secreted by P. aeruginosa that enhances the inflammatory response and causes tissue damage in the host [21]. As shown in Figure 2a, EDTA at the concentrations of 0.075 and $0.15 \mathrm{mM}$, highly inhibited pyocyanin production by the PaM1 strain at $72 \mathrm{~h}$ (by $62 \%$ and $70 \%$, respectively) as compared to the untreated cells. Regarding the PaM5 strain, which was a low pyocyanin producer (Figure 2b), EDTA at both concentrations caused a reduction of approximately $40 \%$ in the production of such pigment, although the difference did not reach statistical significance compared to the untreated cells. 
P. aeruginosa produces and secretes a number of proteases, such as LasA, elastase B (LasB), protease $\mathrm{IV}$, and alkaline protease, which are considered important virulence factors as they damage host tissues and interfere with host antibacterial defense mechanisms [22]. The total proteolytic activity of PaM1 was completely abolished in the presence of either 0.075 or 0.15 mM EDTA (Figure 2a). Similarly, EDTA significantly reduced the proteolytic activity of the PaM5 strain but only at the concentration of $0.15 \mathrm{mM}$ (Figure 2b).

LasA is a zinc-dependent metalloprotease secreted by P. aeruginosa. It exhibits a staphylolytic activity, enhances the elastolytic activity of LasB in vivo, and induces shedding of syndecans, a family of cell surface heparan sulfate proteoglycans, from host cell surfaces [23]. LasA activity of both the PaM1 and PaM5 strains was significantly inhibited in the presence of 0.075 and $0.15 \mathrm{mM}$ EDTA, with a reduction of approximately $70 \%$ and $80 \%$, as compared to the untreated control, respectively (Figure 2a,b). Further experiments were undertaken in order to evaluate whether the reduction of LasA activity was ascribable to the inhibition of protease synthesis or, rather, to the inhibition of the enzyme activity due to zinc chelation by EDTA (Figure S1). To this aim, the assessment of the PaM1 staphylolytic activity was performed in the presence of exogenously added zinc $\left(0.1 \mathrm{mM} \mathrm{ZnSO}_{4}\right)$. When $\mathrm{ZnSO}_{4}$ was added directly in the enzyme assay, at the end of the incubation period $(72 \mathrm{~h})$, no significant increase in LasA activity was observed, suggesting that the low levels of LasA activity detected in the presence of EDTA were likely due to inhibition of protein synthesis and not to the chelation of the enzyme cofactor. In contrast, when $\mathrm{ZnSO}_{4}$ was added at the beginning of the incubation of PaM1 with EDTA, LasA activity was restored (Supplementary Figure S1), indicating that the excess of zinc could overcome the inhibitory effect of EDTA. Overall, these data suggest that EDTA may act by interfering with the expression/procession of LasA protease by PaM1 strain rather than by sequestering the zinc cofactor.

Pyoverdin is a chelator involved in iron binding and cellular uptake in a low-iron environment [24]. EDTA at both concentrations tested did not reduce the level of pyoverdin in culture supernatants of both P. aeruginosa strains (Figure 2a,b).

Studies on mucoid P. aeruginosa isolates have shown that alginate plays a critical role in biofilm establishment and persistence by protecting bacteria against antibiotics and phagocytosis $[25,26]$. Although EDTA did not inhibit the production of alginate in culture supernatants of both strains (Figure 2a,b), it was able to significantly reduce the viscosity of PaM1 culture supernatants at both concentrations tested (Figure 2a).

Finally, EDTA was tested for its antibiofilm activity against the PaM1 strain. A reduction of $40 \%$ and $57 \%$ in PaM1 biofilm formation was observed in the presence of 0.075 and $0.15 \mathrm{mM}$ EDTA, respectively (Figure 2a).

The impact of lin-SB056-1 on the production of virulence factors by PaM1 and PaM5 strains was also evaluated. As reported in Table S2, the peptide at sub-inhibiting concentrations did not reduce the production of any of the virulence factors analyzed for both bacterial strains tested. 

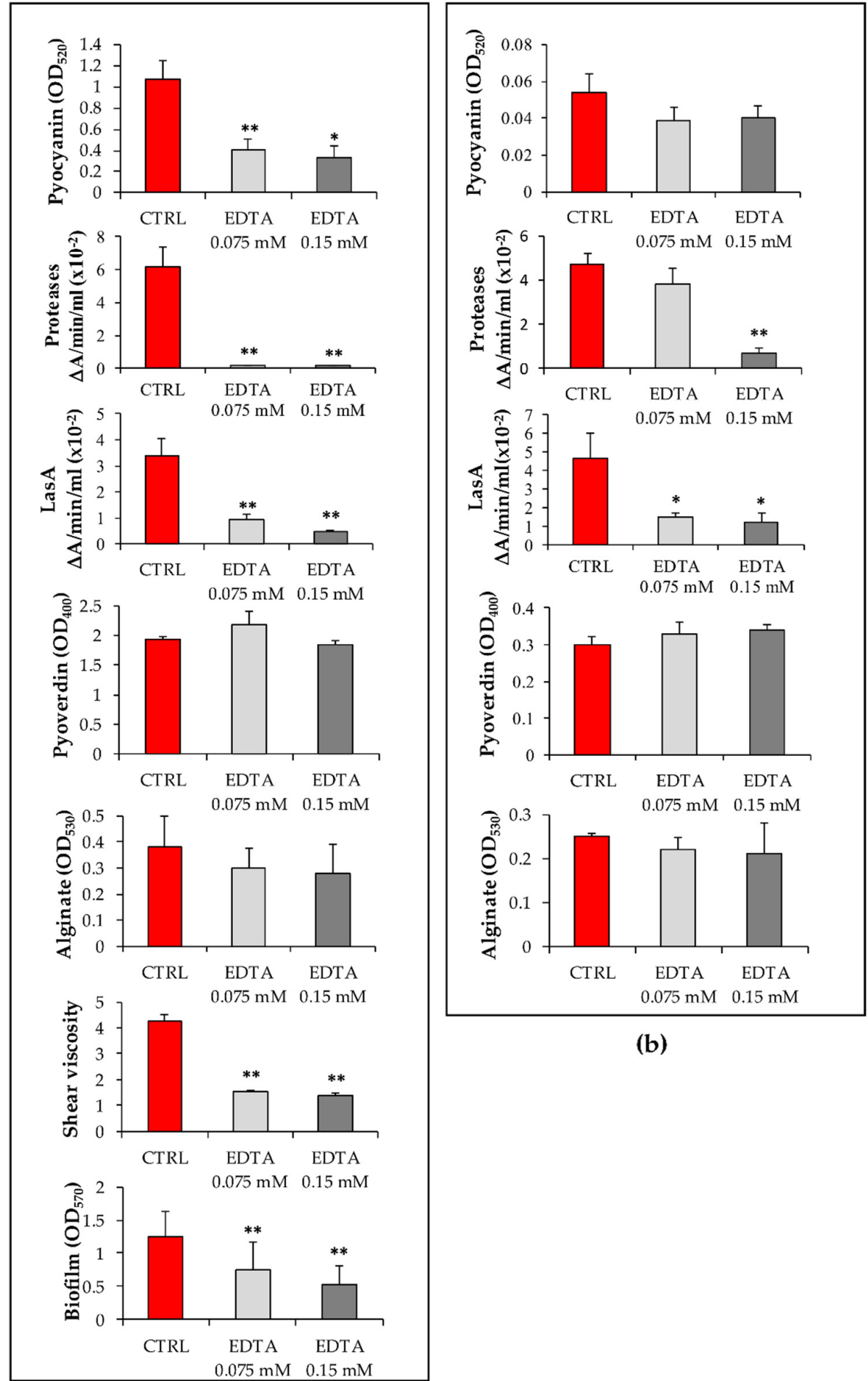

(b)

(a)

Figure 2. Effects of EDTA on virulence factor production by (a) PaM1 and (b) PaM5 strains. PaM1 and PaM5 cultures were incubated at $37^{\circ} \mathrm{C}$ in the presence or absence of EDTA for $72 \mathrm{~h}$. Following incubation, $\mathrm{OD}_{600}$ was measured prior the quantification of the virulence factors in culture supernatants (see the Materials and Methods Section for details). Values obtained were normalized by multiplying them by the ratio between $\mathrm{OD}_{600}$ of the control/OD $\mathrm{OD}_{600}$ of the corresponding EDTA-treated samples and reported as mean +/- SEM of three independent experiments. CTRL: bacteria incubated without EDTA; ${ }^{*} p<0.05,{ }^{* *} p<0.01$ (one-way ANOVA followed by the Tukey-Kramer post-hoc test). 


\section{Discussion}

Similar to CF patients, eradication of chronic P. aeruginosa infection in PCD lungs is hardly obtained, and the reduction of bacterial density during chronic colonization or exacerbations is often the aim of the antimicrobial therapy [3]. In previous studies, we have shown that the combination of lin-SB056-1/EDTA possesses antimicrobial activity against $P$. aeruginosa in artificial sputum medium and prevents $P$. aeruginosa biofilm formation in an in vivo-like three-dimensional (3D) lung epithelial cell model $[16,27]$. Despite resembling the airway mucus, artificial sputum media normally behave like Newtonian fluids lacking many of the intramolecular interactions and covalent cross-links that give respiratory secretions their viscoelastic characteristic [28]. Furthermore, the genotype and physiological state of $P$. aeruginosa cells found in vivo may significantly differ from those of bacteria grown in laboratory media [29]. Hence, in this study, we sought to validate the anti-pseudomonal activity of the lin-SB056-1/EDTA combination in conditions more closely resembling the environment found in vivo. To this aim efficacy of the combination was tested ex vivo, against endogenous P. aeruginosa in the sputum of PCD patients. Differently from artificial sputum medium, patients' sputum contains host/bacterial components such as cell-derived factors, normal flora, inflammatory mediators, proteases, or peptidases that may exert an additional inhibitory effect on the peptide's activity. Nevertheless, herein, we showed that the combination of lin-SB056-1 and EDTA at sub-active and non-cytotoxic concentrations $[16,27]$ determined a significant reduction in P. aeruginosa load in sputa of PCD chronically infected patients, despite certain differences in the level of reduction among different sputum samples being observed. Such differences are not surprising considering that inter-patient variables (e.g., clinical stage and severity of lung infection, bacterial load, sputum sample composition, and consistency) were not standardized in our experiments, in the attempt to mimic conditions found during the actual antimicrobial therapy. The mechanisms of the synergistic effect of EDTA on the peptide's activity might be multiple. Due to the chelation of divalent cations from their binding sites in lipopolysaccharide (LPS), EDTA may destabilize the bacterial outer membrane, thus increasing the permeability to lin-SB056-1 molecules and their interaction with the bacterial membranes. In addition, at least part of the synergistic effect observed in sputum could be ascribed to the ability of EDTA to reduce sputum viscosity, thus favoring peptide diffusion [16]. Finally, EDTA could also neutralize the inhibitory effect of sputum on the peptide's activity, sequestering cations that may interfere with the electrostatic interactions of the peptide with bacterial surface $[9,10]$. The possible use of EDTA in the treatment of pulmonary infections and its safety as an adjuvant has been highlighted in previous in vivo studies [30,31]. For instance, Liu and coworkers demonstrated, in the guinea pig model, that EDTA ( $30 \mathrm{mg} / \mathrm{kg}$ intraperitoneally injected) plus ciprofloxacin $(4 \mu \mathrm{g} / \mathrm{mL}$ administered by inhalation) significantly reduced the P. aeruginosa CFU number per gram of lung tissue as compared to the single treatment groups [31].

Interestingly, the results obtained in this study clearly demonstrated that EDTA could not only favor the activity of lin-SB056-1 in ex vivo conditions, but could also reduce in vitro, at sub-inhibitory concentrations, the production of several P. aeruginosa virulence factors (i.e., pyocyanin, total protease and LasA), which are known to play a crucial role in the pathogenesis of P. aeruginosa infections. The action of EDTA as an anti-virulence molecule could be ascribed to its capacity of binding divalent cations, many of which are critical for the expression/processing of virulence factors of $P$. aeruginosa. In particular, the reduction of pyocyanin observed in the presence of EDTA is in line with previous reports demonstrating a positive correlation between calcium levels and the expression of proteins involved in the pathway of pyocyanin biosynthesis [32]. Analogously, the reduction of proteases by EDTA is in agreement with previous observations reporting that zinc ions are important for the efficient production and processing of different proteases, such as LasA, LasB, and protease IV [19,33].

On the contrary, EDTA did not inhibit pyoverdin production, in agreement with the observation that neither calcium nor magnesium enhances pyoverdin production [34,35]. Interestingly, although EDTA did not inhibit alginate production, it was able to markedly reduce the viscosity of culture supernatants of the PaM1 strain. It can be hypothesized that this effect may be due to the sequestration 
of calcium ions that are crucial for alginate cross-linking [36]. A similar mechanism may be involved in the ability of EDTA to reduce the formation of PaM1 biofilm, confirming previous observations in which EDTA significantly reduced biofilm formation by a mucoid strain of $P$. aeruginosa either in vitro or in a guinea-pig model of lung infection [31]. Overall, the ability of EDTA to reduce the accumulation and/or activity of important virulence factors might contribute to limit the pathogenicity of $P$. aeruginosa.

In conclusion, in the present study, we demonstrated that the lin-SB056-1/EDTA combination is able to significantly reduce P. aeruginosa load in PCD sputum, and that EDTA decreases the production of relevant virulence factors of mucoid P. aeruginosa in vitro. Such results suggest a dual antimicrobial and anti-virulence effect of the lin-SB056-1/EDTA combination and highlight the possible use of EDTA as an adjuvant in the treatment of chronic P. aeruginosa lung infections.

\section{Materials and Methods}

\subsection{Sputum Collection and Treatment}

The sputum samples were collected by spontaneous expectoration from six PCD patients following informed consent. The study was conducted in accordance with the Declaration of Helsinki, and the protocol was approved by the Ethics Committee of Pisa (Protocol number 62532, 11.06.2016). PCD patients included in this study (median age: 34 years) were chronically infected by P. aeruginosa and characterized by frequent relapses of infection. A volume of $0.5-1 \mathrm{~mL}$ of sputum was collected from each patient after interruption (at least 14 days) of the antibiotic therapy regimen. For easier handling of the samples, the dense and sticky sputa were diluted five-fold in sodium phosphate buffer $10 \mathrm{mM}, \mathrm{pH}$ 7.4 (SPB). Samples were plated on cetrimide (Sigma Aldrich, Saint Louis, MO, USA) and MacConkey (Oxoid Basingstoke, Hampshire, UK agar to confirm the presence of P. aeruginosa and assess the mucoid phenotype of the colonies, respectively.

\subsection{Peptide and EDTA Solutions}

Lin-SB056-1 peptide (KWKIRVRLSA-NH ${ }_{2}$ ) was purchased from Peptide Protein Research, Ltd. (Fareham, UK) with a purity of $98 \%$. EDTA (disodium salt) was obtained from Sigma-Aldrich. A stock solution of disodium-EDTA $(0.5 \mathrm{M})$ was prepared in milli-Q water by adjusting the $\mathrm{pH}$ to 8.0 with $\mathrm{NaOH}$ (Sigma-Aldrich). The stock solution was then diluted in milli-Q water to obtain a working solution of $50 \mathrm{mM}$ that was sterilized and stored at $4{ }^{\circ} \mathrm{C}$.

\subsection{Susceptibility Testing}

Identification and susceptibility testing of $P$. aeruginosa strains isolated from sputum samples (PaM1, PaM2, PaM3, PaM4, PAM5, PaM6) were performed by MALDI-TOF (Bruker Daltonics, Bremen, Germany) and VITEK 2 automatic instruments (BioMerieux, Lyon, France), respectively (Table S1). Determination of minimum inhibitory concentration (MIC) of EDTA towards PaM1 and PaM5 strains was performed according to the standard microdilution method in Muller-Hinton broth (Oxoid) [37]. The MIC was defined as the lowest concentration of EDTA that completely inhibited visible growth of bacteria after $24 \mathrm{~h}$ of incubation.

\subsection{Bactericidal Assay in Patients' Sputum}

An aliquot of each PCD sputum was serially diluted and plated on selective cetrimide agar, to assess the CFU number of endogenous P. aeruginosa at time 0 . After that, a volume of $90 \mu \mathrm{L}$ of diluted (1:5) sputum of each patient was incubated with sub-bactericidal concentrations of peptide and EDTA, used alone or in combination, for $1.5 \mathrm{~h}$ at $37^{\circ} \mathrm{C}$. Following incubation, samples were serially diluted and plated on selective cetrimide agar for assessing the P. aeruginosa CFU number. 


\subsection{Assays for Evaluation of Virulence Factors in Culture Supernatants}

Colonies of mucoid strains PaM1 and PaM5 grown on MacConkey agar were suspended in Luria Bertani (LB) broth (Sigma-Aldrich) to obtain an $\mathrm{OD}_{600}$ of 0.1. Cultures were incubated in the presence or in the absence of EDTA $(0.075$ or $0.15 \mathrm{mM})$ in static conditions at $37^{\circ} \mathrm{C}$ for $72 \mathrm{~h}$. Following incubation, the $\mathrm{OD}_{600}$ of the cultures was determined to account for bacterial density. After that, cultures were centrifuged at $10,000 \times g$ for $20 \mathrm{~min}$ at room temperature and culture supernatants were used for the quantification of virulence factors. The same protocol was followed to evaluate the eventual effects of linSB056-1 on the production of virulence factors. To this aim, the peptide was added to PaM1 and PaM5 cultures at the concentration of $6.25 \mu \mathrm{g} / \mathrm{mL}$ and $12.5 \mu \mathrm{g} / \mathrm{mL}$ that were sub-inhibitory for both bacterial strains.

Pyocyanin was extracted from cell-free supernatants with subsequent exposure to chloroform and $0.2 \mathrm{~N}$ hydrochloric acid (Sigma-Aldrich) and quantified at $\mathrm{OD}_{520} \mathrm{~nm}$, as previously described [38].

Total proteolytic activity was determined using a modified skim milk assay [39]. Briefly, culture supernatants of PaM1 and PaM5 strains $(0.5 \mathrm{~mL})$ were incubated with $0.5 \mathrm{~mL}$ skim milk (Sigma-Aldrich) $(1.25 \%)$ at $37^{\circ} \mathrm{C}$ for $30 \mathrm{~min}$ and turbidity was measured at $\mathrm{OD}_{600} \mathrm{~nm}$. The decrement in turbidity due to proteolytic activity was expressed as $\triangle \mathrm{A} / \mathrm{min} / \mathrm{mL}$.

Secreted LasA of $P$. aeruginosa has a staphylolytic activity, i.e., it causes a decrement in the $\mathrm{OD}_{600}$ of a culture of Staphylococcus aureus. LasA activity was assessed by evaluating the ability of cell-free supernatants from P. aeruginosa exposed or not exposed to EDTA to lyse boiled cells (intact) of $S$. aureus American Type Culture Collection (ATCC) 33591 and expressed as $\Delta \mathrm{A} / \mathrm{min} / \mathrm{mL}$ [40]. Due to the role of zinc as a cofactor of LasA, in some experiments, the staphylolytic activity in the presence of EDTA was evaluated by adding $0.1 \mathrm{mM} \mathrm{ZnSO}_{4}$ (Sigma-Aldrich) to the enzyme assay.

Pyoverdin was quantified by measuring the $\mathrm{OD}_{400}$ of cell-free supernatants [41].

The quantification of alginate was performed by carbazole-borate assay according to Heidari et al. [42]. Shear viscosity of culture supernatants was assessed by rheometric measurement at $25^{\circ} \mathrm{C}$, applying a shear stress of $1 \mathrm{~Pa} / \mathrm{s}$ on $150 \mu \mathrm{l}$ of supernatant using a gap between the rheometer plates of $52 \mu \mathrm{m}$ (Rheometer Scientific RM500, Reologica Instruments AB, Lund, Sweden).

The value obtained for each virulence factor was multiplied by the ratio $\mathrm{OD}_{600}$ of the control/OD 600 of the sample, to normalize for small differences in the culture densities between the controls and the EDTA-exposed samples after $72 \mathrm{~h}$ of incubation.

\subsection{Biofilm Inhibition Assay}

P. aeruginosa PaM1 grown in tryptone soy broth (TSB) for $48 \mathrm{~h}$ at $37^{\circ} \mathrm{C}$ was diluted 1:20 in TSB supplemented with $0.25 \mathrm{mM} \mathrm{CaCl}_{2}$. Bacterial suspensions were inoculated into flat-bottom polystyrene 96-well microplates (Corning Costar, Lowell, MA, USA) in the absence (negative control) or in the presence of EDTA at sub-inhibiting concentrations (0.075 and $0.15 \mathrm{mM})$. Microplates were incubated statically at $37^{\circ} \mathrm{C}$ for $48 \mathrm{~h}$ and biofilm biomass was estimated by crystal violet (CV) (Sigma-Aldrich) staining assay, as previously described [43].

\subsection{Statistical Analysis}

Data reported in Figure 1 represent the mean of 6 experiments done in duplicate. Figure 2 and Supplementary Figure S1 depict the data obtained from three independent experiments, while Table S2 reports the mean of two independent experiments. Differences between mean values of groups were evaluated by one-way analysis of variance (ANOVA) followed by the Tukey-Kramer post-hoc test. A $p$-value $<0.05$ was considered statistically significant. Data analysis was performed with GraphPad In Stat (GraphPad Software, La Jolla, CA, USA). 
Supplementary Materials: Supplementary Materials can be found at http://www.mdpi.com/1422-0067/21/1/69/s1. Table S1: Patients' information, colony phenotype, and resistance profile of P. aeruginosa strains isolated from PDC sputum; Table S2: Effects of lin-SB056-1 on the production of virulence factors by PaM1 and PaM5 strains; Figure S1: Effect of exogenously added Zinc on LasA staphylolytic activity of PaM1 strain in the presence of EDTA.

Author Contributions: Conceptualization, G.M., S.E., M.P. (Massimo Pifferi), and G.B.; methodology, G.M., L.G., M.P. (Martina Piras), E.K., A.M., D.P.; validation, G.M., S.E., M.P. (Massimo Pifferi), and G.B.; formal analysis, G.M., L.G., M.P. (Martina Piras), E.K. and F.C.; writing-original draft preparation, G.M. and G.B.; writing-review and editing, L.G., S.E., E.K., F.C., and M.P. (Martina Piras), supervision, M.P. (Massimo Pifferi), S.E., and G.B.; funding acquisition, G.B. All authors have read and agreed to the published version of the manuscript.

Funding: This research was funded by the University of Pisa, grant number PRA 2017_18.

Conflicts of Interest: The authors declare no conflict of interest. The funders had no role in the design of the study; in the collection, analyses, or interpretation of data; in the writing of the manuscript, or in the decision to publish the results.

\section{Abbreviations}

$\begin{array}{ll}\text { ATCC } & \text { American Type Culture Collection } \\ \text { AMPs } & \text { Antimicrobial peptides } \\ \text { ANOVA } & \text { Analysis of variance } \\ \text { CF } & \text { Cystic fibrosis } \\ \text { CFU } & \text { Colony forming units } \\ \text { CV } & \text { Crystal violet } \\ \text { EDTA } & \text { Ethylenediaminetetraacetic acid } \\ \text { LB } & \text { Luria-Bertani broth } \\ \text { LPS } & \text { Lipopolysaccharide } \\ \text { MIC } & \text { Minimum Inhibitory Concentration } \\ \text { OD } & \text { Optical density } \\ \text { PCD } & \text { Primary Ciliary Dyskinesia } \\ \text { SPB } & \text { Sodium Phosphate Buffer } \\ \text { TSB } & \text { Tryptone Soy Broth }\end{array}$

\section{References}

1. Wijers, C.D.M.; Chmiel, J.F.; Gaston, B.M. Bacterial infections in patients with primary ciliary dyskinesia: Comparison with cystic fibrosis. Chron. Respir. Dis. 2017, 14, 392-406. [CrossRef]

2. Cohen-Cymberknoh, M.; Weigert, N.; Gileles-Hillel, A.; Breuer, O.; Simanovsky, N.; Boon, M.; De Boeck, K.; Barbato, A.; Snijders, D.; Collura, M.; et al. Clinical impact of Pseudomonas aeruginosa colonization in patients with primary ciliary dyskinesia. Respir. Med. 2017, 131, 241-246. [CrossRef] [PubMed]

3. Crowley, S.; Holgersen, M.G.; Nielsen, K.G. Variation in treatment strategies for the eradication of Pseudomonas aeruginosa in primary ciliary dyskinesia across European centers. Chron. Respir. Dis. 2019, 16, 1-8. [CrossRef] [PubMed]

4. Bianconi, I.; Jeukens, J.; Freschi, L.; Alcalá-Franco, B.; Facchini, M.; Boyle, B.; Molinaro, A.; Kukavica-Ibrulj, I.; Tümmler, B.; Levesque, R.C.; et al. Comparative genomics and biological characterization of sequential Pseudomonas aeruginosa isolates from persistent airways infection. BMC Genom. 2015, 16, 1105-1118. [CrossRef]

5. Alanin Mikkel, C. Bacteriology and treatment of infections in the upper and lower airways in patients with primary ciliary dyskinesia: Addressing the paranasal sinuses. Dan. Med. J. 2017, 64, 5361-5378.

6. Haney, E.F.; Mansour, S.C.; Hancock, R.E. Antimicrobial Peptides: An introduction. Methods Mol. Biol. 2017, 1548, 3-22. [CrossRef]

7. Grassi, L.; Di Luca, M.; Maisetta, G.; Rinaldi, A.C.; Esin, S.; Trampuz, A.; Batoni, G. Generation of persister cells of Pseudomonas aeruginosa and Staphylococcus aureus by chemical treatment and evaluation of their susceptibility to membrane-targeting agents. Front. Microbiol. 2017, 8, 1917. [CrossRef]

8. Grassi, L.; Maisetta, G.; Esin, S.; Batoni, G. Combination strategies to enhance the efficacy of antimicrobial peptides against bacterial biofilms. Front. Microbiol. 2017, 8, 2409. [CrossRef] 
9. Maisetta, G.; Di Luca, M.; Esin, S.; Florio, W.; Brancatisano, F.L.; Bottai, D.; Campa, M.; Batoni, G. Evaluation of the inhibitory effects of human serum components on bactericidal activity of human beta defensin 3 . Peptides 2008, 29, 1-6. [CrossRef]

10. Batoni, G.; Maisetta, G.; Esin, S.; Campa, M. Human beta-defensin-3: A promising antimicrobial peptide. Mini Rev. Med. Chem. 2006, 6, 1063-1073. [CrossRef]

11. Sommer, L.M.; Alanin, M.C.; Marvig, R.L.; Nielsen, K.G.; Høiby, N.; von Buchwald, C.; Molin, S.; Johansen, H.K. Bacterial evolution in PCD and CF patients follows the same mutational steps. Sci. Rep. 2016, 28, 28732. [CrossRef] [PubMed]

12. Waters, V.; Smyth, A. Cystic fibrosis microbiology: Advances in antimicrobial therapy. J. Cyst. Fibros. 2015, 14, 551-560. [CrossRef] [PubMed]

13. Lefebvre, E.; Vighetto, C.; Di Martino, P.; Larreta Garde, V.; Seyer, D. Synergistic antibiofilm efficacy of various commercial antiseptics, enzymes and EDTA: A study of Pseudomonas aeruginosa and Staphylococcus aureus biofilms. Int. J. Antimicrob. Agents 2016, 48, 181-188. [CrossRef] [PubMed]

14. Percival, S.L.; Salisbury, A.M. The Efficacy of tetrasodium EDTA on biofilms. Adv. Exp. Med. Biol. 2018, 1057, 101-110. [CrossRef] [PubMed]

15. Ferrero, M.E. Rationale for the successful management of EDTA chelation therapy in human burden by toxic metals. Biomed. Res. Int. 2016, 2016, 8274504. [CrossRef]

16. Maisetta, G.; Grassi, L.; Esin, S.; Serra, I.; Scorciapino, M.A.; Rinaldi, A.C.; Batoni, G. The semi-synthetic peptide lin-SB056-1 in combination with EDTA exerts strong antimicrobial and antibiofilm activity against Pseudomonas aeruginosa in conditions mimicking cystic fibrosis sputum. Int. J. Mol. Sci. 2017, 16, 1994. [CrossRef]

17. Bush, A.; Payne, D.; Pike, S.; Jenkins, G.; Henke, M.O.; Rubin, B.K. Mucus properties in children with primary ciliary dyskinesia: Comparison with cystic fibrosis. Chest 2006, 129, 118-123. [CrossRef]

18. Kim, W.D. Lung mucus: A clinician's view. Eur. Respir. J. 1997, 10, 1914-1917. [CrossRef]

19. Olson, J.C.; Ohman, D.E. Efficient production and processing of elastase and LasA by Pseudomonas aeruginosa require zinc and calcium ions. J. Bacteriol. 1992, 174, 4140-4147. [CrossRef]

20. Guragain, M.; King, M.M.; Williamson, K.S.; Pérez-Osorio, A.C.; Akiyama, T.; Khanam, S.; Patrauchan, M.A.; Franklin, M.J. The Pseudomonas aeruginosa PAO1 two-component regulator CarSR regulates calcium homeostasis and calcium-induced virulence factor production through its regulatory targets CarO and CarP. J. Bacteriol. 2016, 198, 951-963. [CrossRef]

21. Rada, B.; Leto, T.L. Pyocyanin effects on respiratory epithelium: Relevance in Pseudomonas aeruginosa airway infections. Trends Microbiol. 2013, 21, 73-81. [CrossRef] [PubMed]

22. Tingpej, P.; Smith, L.; Rose, B.; Zhu, H.; Conibear, T.; Al Nassafi, K.; Manos, J.; Elkins, M.; Bye, P.; Willcox, M.; et al. Phenotypic characterization of clonal and nonclonal Pseudomonas aeruginosa strains isolated from lungs of adults with cystic fibrosis. J. Clin. Microbiol. 2007, 45, 1697-1704. [CrossRef] [PubMed]

23. Park, P.W.; Pier, G.B.; Preston, M.J.; Goldberger, O.; Fitzgerald, M.L.; Bernfield, M. Syndecan-1 shedding is enhanced by LasA, a secreted virulence factor of Pseudomonas aeruginosa. J. Biol. Chem. 2000, 275, 3057-3064. [CrossRef] [PubMed]

24. Edgar, R.J.; Hampton, G.E.; Garcia, G.P.C.; Maher, M.J.; Perugini, M.A.; Ackerley, D.F.; Lamont, I.L. Integrated activities of two alternative sigma factors coordinate iron acquisition and uptake by Pseudomonas aeruginosa. Mol. Microbiol. 2017, 106, 891-904. [CrossRef]

25. Hodges, N.A.; Gordon, C.A. Protection of Pseudomonas aeruginosa against ciprofloxacin and beta-lactams by homologous alginate. Antimicrob. Agents Chemother. 1991, 35, 2450-2452. [CrossRef] [PubMed]

26. Leid, J.G.; Willson, C.J.; Shirtliff, M.E.; Hassett, D.J.; Parsek, M.R.; Jeffers, A.K. The exopolysaccharide alginate protects Pseudomonas aeruginosa biofilm bacteria from IFN-gamma-mediated macrophage killing. J. Immunol. 2005, 175, 7512-7518. [CrossRef]

27. Grassi, L.; Batoni, G.; Ostyn, L.; Rigole, P.; Van den Bossche, S.; Rinaldi, A.C.; Maisetta, G.; Esin, S.; Coenye, T.; Crabbé, A. The antimicrobial peptide lin-SB056-1 and its dendrimeric derivative prevent Pseudomonas aeruginosa biofilm formation in physiologically relevant models of chronic infections. Front. Microbiol. 2019, 10, 198. [CrossRef]

28. Müller, A.; Wenzel, M.; Strahl, H.; Grein, F.; Saaki, T.N.V.; Kohl, B.; Siersma, T.; Bandow, J.E.; Sahl, H.G.; Schneider, T.; et al. Daptomycin inhibits cell envelope synthesis by interfering with fluid membrane microdomains. Proc. Natl. Acad. Sci. USA 2016, 113, 7077-7086. [CrossRef] 
29. Sajjan, U.S.; Tran, L.T.; Sole, N.; Rovaldi, C.; Akiyama, A.; Friden, P.M.; Forstner, J.F.; Rothstein, D.M. P-113D, an antimicrobial peptide active against Pseudomonas aeruginosa, retains activity in the presence of sputum from cystic fibrosis patients. Antimicrob. Agents Chemother. 2001, 45, 3437-3444. [CrossRef]

30. Hachem, R.; Bahna, P.; Hanna, H.; Stephens, L.C.; Raad, I. EDTA as an adjunct antifungal agent for invasive pulmonary aspergillosis in a rodent model. Antimicrob. Agents Chemother. 2006, 50, 1823-1827. [CrossRef]

31. Liu, Z.; Lin, Y.; Lu, Q.; Li, F.; Yu, J.; Wang, Z.; He, Y.; Song, C. In vitro and in vivo activity of EDTA and antibacterial agents against the biofilm of mucoid Pseudomonas aeruginosa. Infection 2017, 45, 23-31. [CrossRef] [PubMed]

32. Sarkisova, S.; Patrauchan, M.A.; Berglund, D.; Nivens, D.E.; Franklin, M.J. Calcium-induced virulence factors associated with the extracellular matrix of mucoid Pseudomonas aeruginosa biofilms. J. Bacteriol. 2005, 187, 4327-4337. [CrossRef] [PubMed]

33. D’Orazio, M.; Mastropasqua, M.C.; Cerasi, M.; Pacello, F.; Consalvo, A.; Chirullo, B.; Mortensen, B.; Skaar, E.P.; Ciavardelli, D.; Pasquali, P.; et al. The capability of Pseudomonas aeruginosa to recruit zinc under conditions of limited metal availability is affected by inactivation of the ZnuABC transporter. Metallomics 2015, 7, 1023-1035. [CrossRef]

34. Marquart, M.E.; Dajcs, J.J.; Caballero, A.R.; Thibodeaux, B.A.; O'Callaghan, R.J. Calcium and magnesium enhance the production of Pseudomonas aeruginosa protease IV, a corneal virulence factor. Med. Microbiol. Immunol. 2005, 194, 39-45. [CrossRef] [PubMed]

35. Laux, D.C.; Corson, J.M.; Givskov, M.; Hentzer, M.; Møller, A.; Wosencroft, K.A.; Olson, J.C.; Krogfelt, K.A.; Goldberg, J.B.; Cohen, P.S. Lysophosphatidic acid inhibition of the accumulation of Pseudomonas aeruginosa PAO1 alginate, pyoverdin, elastase and LasA. Microbiology 2002, 148, 1709-1723. [CrossRef]

36. Körstgens, V.; Flemming, H.C.; Wingender, J.; Borchard, W. Influence of calcium ions on the mechanical properties of a model biofilm of mucoid Pseudomonas aeruginosa. Water Sci. Technol. 2001, 43, 49-57. [CrossRef]

37. European Committee for Antimicrobial Susceptibility Testing (EUCAST) of the European Society of Clinical Microbiology and Infectious Diseases (ESCMID). EUCAST definitive document E. Def 1.2, May 2000: Terminology relating to methods for the determination of susceptibility of bacteria to antimicrobial agents. Clin. Microbiol. Infect. 2000, 6, 503-508. [CrossRef]

38. Essar, D.W.; Eberly, L.; Hadero, A.; Crawford, IP. Identification and characterization of genes for a second anthranilate synthase in Pseudomonas aeruginosa: Interchangeability of the two anthranilate synthases and evolutionary implications. J. Bacteriol. 1990, 172, 884-900. [CrossRef]

39. El-Mowafy, S.A.; Abd, E.; Galil, K.H.; El-Messery, S.M.; Shaaban, M.I. Aspirin is an efficient inhibitor of quorum sensing, virulence and toxins in Pseudomonas aeruginosa. Microb. Pathog. 2014, 74, 25-32. [CrossRef]

40. Kessler, E.; Safrin, M.; Olson, J.C.; Ohman, D.E. Secreted LasA of Pseudomonas aeruginosa is a staphylolytic protease. J. Biol. Chem. 1993, 268, 7503-7508. [CrossRef]

41. Cox, C.D.; Adams, P. Siderophore activity of pyoverdin for Pseudomonas aeruginosa. Infect. Immun. 1985, 48, 130-138.

42. Heidari, A.; Noshiranzadeh, N.; Haghi, F.; Bikas, R. Inhibition of quorum sensing related virulence factors of Pseudomonas aeruginosa by pyridoxal lactohydrazone. Microb. Pathogen. 2017, 112, 103-110. [CrossRef] [PubMed]

43. Maisetta, G.; Batoni, G.; Caboni, P.; Esin, S.; Rinaldi, A.C.; Zucca, P. Tannin profile, antioxidant properties, and antimicrobial activity of extracts from two Mediterranean species of parasitic plant Cytinus. BMC Complement. Altern. Med. 2019, 19, 82-93. [CrossRef] [PubMed]

(C) 2019 by the authors. Licensee MDPI, Basel, Switzerland. This article is an open access article distributed under the terms and conditions of the Creative Commons Attribution (CC BY) license (http://creativecommons.org/licenses/by/4.0/). 